\title{
NETWORK RESEARCH IN LAW: CURRENT SCHOLARSHIP IN REVIEW Shisong Jiang
}

Ph.D. Candidate in International Law, Institute of Law, Politics, and Development, Scuola Superiore Sant'Anna (Italy), and Faculty of Law, University of Antwerp (Belgium).

Email: shisong.jiang@santannapisa.it

\author{
Article History: Received on $30^{\text {th }}$ August 2019, Revised on $30^{\text {th }}$ September 2019, Published on $14^{\text {th }}$ October 2019
}

\begin{abstract}
Purpose of the study: The aim of this paper is twofold and while one is more analytically conspicuous, another is rather devised to be more connotatively ambitious. As to the former one, it intends to contribute to the literature on the interdisciplinary collaboration between network science and legal science by comprehensively reviewing and discussing the existing literature as well as the relevant academic activities. More importantly, the entire process of "looking back" is underpinned by the anticipation of "moving forward" incarnating as an invitation to this emerging yet still the underexplored field of study.
\end{abstract}

Methodology: To achieve its aims, this study primarily adopts the scoping review methodology to map the extant literature and relevant research activities in this emergent area of research. The data solicited for this study was thus qualitative in nature and mainly generated from journal articles, books, book chapters, and conference proceedings on the topic in question. In addition, Internet sources like blog pages and university websites were involved as well.

Main findings: The comprehensive review conducted by this study recognized that the origin, evolution, and development of network studies of law have been in line with the mainstream of network analysis/science, especially in terms of the historical timeline and scope. One of the most salient characteristics of the status quo of the network analysis in legal scholarship refers to the dominant analytical focus on the structural dimension and its implications for law. However, this study also identified the fragmented attributes of this interdisciplinary enterprise in which the conceptual and methodological understandings have been shaped in different ways.

Applications of this study: Given the epistemic and pragmatical significance of integrating network thinkings and methods with legislation, adjudication, and implementation, this study is highly relevant and meaningful for both legal practitioners and (socio-)legal academics who obtain the specific intention of updating the landscape of this field.

Novelty/Originality of this study: Against the general backdrop of the increasing number of studies that apply network theories and methods to legal topics, this study is initially novel in the sense that it attempts to uncover the intellectual trajectory of the network analysis in law by reviewing the existing literature and the relevant activities in the academia.

Keywords: network analysis, legal scholarship, intellectual trajectory, structuralism, institutionalization, literature review.

\section{INTRODUCTION}

In light of the overwhelming recognition of the rise of the network society (Castells, 2000), the various forms of intellectual acts ranging from natural, social, engineering and informational sciences, therefore, have been notably influenced (Christakis \& Fowler, 2011). Apart from the enormous effects on the extant disciplines, a "new" science of networks commits itself to the network-based theoretical formulations as well as their corresponding applications by mainly borrowing, synthesizing and refining graph theory in discrete mathematics, sociology, and anthropology (Watts, 2004). Accordingly, a network paradigm that focuses on actors and ties at the multidimensional level has shaped its distinctive contour among different disciplines and fields of study. Indeed, the development of the network research varies from case to case among social sciences (for general analysis, see, Borgatti et al., 2009). It is, therefore, vital for us to 'first recognize the ways that the idea of the network must be placed within a larger understanding of its disciplinary contexts' (Knox et al., 2006: 133). For instance, comparatively speaking, the network paradigm in organizational research and public administration, which heavily draws upon the so-called "three traditions of network research", i.e., the sociological, political science and public management tradition (Berry et al., 2004), is more prosperous. Similarly, the notion of the network has been largely incorporated into international relations scholarship (e.g., Hafner-Burton et al., 2009). Besides, the historical network analysis, as one of the representatives for these remainders still struggling to legitimize the significance of various networks, is also strictly keeping in pace with the network fashion.

Against this general backdrop, it seems unsurprising that the appearance of the notion of the network has also become frequent in legal scholarship (e.g., Dothan, 2018; Puig, 2018). Comparing with other social sciences, however, network analysis in the legal domain is currently taking a laggard position. The relative underdevelopment of network analysis in the legal domain could be reflected by the scarce presence of the review paper which is, to some extent, a visual symbol for a certain level of intellectual maturity of an academic enterprise (Gallagher \& Anderson, 1999). Indeed, there are very few legal research projects that devote themselves to record the intellectual footprint of the notion of network in law (e.g., Petersen \& Towfigh, 2017). On the one hand, this status quo is paradoxically incompatible with the ongoing trend in terms of the constant increase of the scientific products of network analysis in law. On the other hand, it is also not the appropriate position to embrace the potential benefits, pragmatically speaking, derived from the particular concentration on the notion of network for legal science. To sum up, we are now missing a comprehensive landscape of the network 
research on law, which would be one of the primary sources of misunderstanding and confusion in this emerging field of research.

Therefore, this paper intends to uncover the intellectual trajectory of the network analysis in law by reviewing the existing literature. To this end, the rest of this paper is organized in the following manner. The origin of network analysis in law is explored in Section 2. Based on this, Section 3 analyzes the notion of the network in legal scholarship explicitly. Section 4 summarizes the main content of network analysis in law, which is followed by Section 5, explaining the "institutionalization symptom" of network analysis in law. Finally, Section 6 warps up the present study with a conclusion that is supplemented by a concise reflection on the limitations of this study as well as the potential directions of future research.

\section{THE ORIGIN OF THE NETWORK ANALYSIS IN LAW}

In comparison with the relative prosperity in terms of the literature on the historical evolution and development of network science (e.g., Lewis, 2009), the integration of legal science with network science, however, has remained silent in this regard. So far, there has been no literature introducing its intellectual history explicitly. As to the possible reasons, it might firstly relate to the fact that network studies in (socio-)legal context are still at its early stage in which the existing literature itself is witnessing a process of creating the history or even prehistory. Furthermore, scholars who have paid attention to both law and networks might be unaware of the underlying collective nature of their research as an independent research orientation or field. However, by taking the evolving timeline of general network studies as a reference point (Freeman, 2011), it is possible to provide the network research on the law with a rough historical clue.

The most primitive form of network studies can find its roots as far back as 1736 when Leonhard Euler applied graph theory to solve the problem of how best to circumnavigate the Bridges of Königsberg. After more than 200 years, network thinking was finally conferred new life by social scientists. Even though sociometry, the first incarnation of the modern network studies, was generated in the 1930s, some network scientists believe that it was not until the contributions of Harrison White and his students in 1970s, network studies were settled down, embraced a standard paradigm and became widely recognized as a field of research (Ibid). Based on this brief retrospect as well as my retrieval for this research, it is safe to say that scholars who pay attention to the topics of both law and networks have followed the main steps of the general intellectual movement in network studies. For instance, Social Networks, the premier and also leading journal for the study of social networks, published Peter Harris (1982)'s paper which diachronically discusses the structural change in the communication of precedent among state supreme courts in the United States in 1982. This kind of precedent studies is actually in line with the popularity of legal citation studies that can be traced back to at least the 1950s. However, as Ryan Whalen (2016: 548) states, 'early works in this vein paid limited attention to the network structure created by case law citations, but focused instead on how citations accrued over time, and how judges decided which cases to cite.' Considering all, the network research on law, therefore, has not entered the period of rapid development until the late 1990s. After 2000, relevant research outcomes, including various topics and themes, have increased exponentially.

Among others, it is noteworthy that the brisk of the evolution of socio-legal scholarship could be considered as the most illuminative factor of influencing the spread of network thinking in law. Nikas Luhmann articulated his sociological theory of law in the late 1980s, which applies systems theory to structures, processes, and development of legal systems. The systems theory of law, similar to the Gunther Teubner's autopoietic theory of law, is one of the most important theories to generate a particular call for a structural perspective on the law. Karl-Heinz Ladeur further developed Luhmann's systems theory of law as a postmodern legal theory which refers to the network concept as a fundamental concept (for details, see below). In addition, Bruno Latour's Actor-Network Theory (ANT) 'treats law as a network of people and of things in which legality is not a field to be studied independently, but is instead a way in which the world is assembled, an attribute that is attached to events, people, documents, and other objects' (Levi and Valverde, 2008: 38). Besides, Roger Cotterrell argues for a "law-and-community approach", which positions social relations as the unit of study and claims that "complex networks of community may present a picture of moral confusion or contradiction, reflected in the law relating to these networks' (Cotterrell, 2008: 12).

\section{THE NOTION OF NETWORK IN LEGAL SCHOLARSHIP}

Similar to the network research in other fields, it is impossible to beg the question of how the notion of a network is perceived in legal studies. Generally speaking, there are different ways of utilizing the term "network" in the entire academia, regardless of discipline or field of study. In other words, there is no consensus on a universal definition of network and the perception of the notion of network remains divergent. Roughly speaking, a network is referred to as a set of nodes (or actors) and relationships between these nodes. This literal meaning is of importance and has already been accepted by sociology, network science, and many other disciplines. Beyond this definitional issue, the epistemological transformation in terms of the conceptual dimension of the notion of network is perhaps even more crucial. Because the notion of network could be treated as 'a powerful way of rephrasing basic issues of social theory, epistemology, and philosophy' (Latour, 2011:2).

Indeed, the legal world has also been to some extent reshaped by the involvement of the notion of the network. In detail, it firstly bears some similarities with the overall situation experienced by other disciplines. The simplest definition of 
network in legal studies also refers to the combination of nodes and ties. It is worth noting that nodes in this regard do not only refer to all kinds of legal actors (including institutions) but also the written and unwritten laws. Ties represent numerous relations among them. The macro picture of this field of research tells that the employment of networks is not unified at all. What is even worse is that there is a paucity of literature on this conceptual question. Under such circumstances, the majority of scholars in this field take the notion of network for granted and directly and uncritically adopt those understandings of networks from the existing discussions in other relevant areas. Thanks to the intellectual borrowings from other areas in which the term network is utilized in a rather hypertrophic and ambiguous way, it is difficult for lawyers to deal with this term for law's inherent resistance to such ambiguity (Druey, 2009; Teubner, 2009b). Moreover, it is also associated with the fact that the majority of the network research in legal studies is the application of SNA as merely a method. By applying this method, some legal topics or issues could be discussed and understood in the framework of network terminologies and theories.

In addition, the metaphorical understandings of the network (Erickson, 2012) have been cultivated from a legal perspective in the past decades. As a matter of fact, law is not unfamiliar with metaphorization in a general sense. On the contrary, 'lawyers, judges, and law professors have long resorted to metaphors of webs, trees, and bramble bushes to evoke the structure of law'(Smith, 2005: 26). Such metaphors are powerful tools for them to make sense of the world by shaping their individual perceptions. The network metaphor used to be the mutual origin of the emerging concerns of 'the hybridity of the reality it sets out to describe' in those neighboring disciplines (Kemmerer, 2009: 441). Legal science is not exceptional. It has actually brought many different insights to legal scholarship, as 'the plurality of the network metaphor becomes visible in images used by lawyers as a means to visualize the network concept - or enforced by ththe ose lawyers upon their readers indirectly' (Ibid: 442). The transformative process from the network metaphor to the network concept in the legal context is correspondingly a reflective image indicating how the network-like phenomenon is addressed by legal ideas. The network-like phenomenon is closely associated with, for instance, the increasing role of civil society, plurality of courts at all levels, overlap or collision of the various governance regimes, and so forth. It requires a perceptive shift of law from the mode of hierarchy and pyramid to network.

Yet, unlike the perceptions above, network as a concept seems rather more attractive for legal scholars. One of the most outstanding representatives who have insisted on the importance of the concept of the network for legal science should refer to Karl-Heinz Ladeur. He conceptualizes network, the most central concept of his work, as an omnibus concept by which some extensive insights at all levels are contained (Kjaer, 2009). For Ladeur, the concept of network 'may be understood to describe a process of observation and operation within empirically detectable network structures in the real world' from a sociological perspective, whereas it also 'describes the mode of thinking itself and thus constitutes an epistemological concept' (Augsherg et al., 2009: 305, 308). By the way, Ladeur (2007) blends both perspectives by referring to "social epistemology". Based on the dual understandings, a "thinking in networks" approach that attacks the traditional yet still prevalent "thinking in states" approach in law, especially in international law, has been formulated as a legal theory (Ladeur, 1997). The network concept in Ladeur's discourse is widely applied to European (administrative), international and transnational law, and has increasing effects on the evolution and development of global administrative law. To make a long story short, Ladeur's intellectual efforts can be summarized as a process of legally conceptualizing network in public law, which have given rise to both appreciation and controversies.

Gunther Teubner, Professor of Private Law and Legal Sociology who is also extensively engaged with research on networks, accuses law as a co-producer of network failure by questioning whether the network concept is legally fruitless from a private law perspective (Teubner, 2009a). His stance on whether the network is a legal concept is very typical among private law scholars. For them, it is certain that 'network is not a legal concept' (Buxbaum, 1993). This common certainty, however, is merely seen as the starting point for lawyers to scrutinize law's capacity of reflecting the network phenomenon (Amstutz and Teubner, 2009: ix). For instance, Teubner further devotes himself to what socio-legal scholars call a "contractual network" and emphasizes his own version of the concept of network from a perspective of sociological jurisprudence. He states that "in my opinion, "network" is not suited to play the role of a technical legal concept. Network traverse private law concepts. Legally speaking, they can take the form of corporate contractual or tortious special relationships. For this reason alone, legal doctrine cannot merely adopt the term "network" as a legal concept' (Teubner, 2009b: 14).

\section{THE CONTENTS OF THE NETWORK ANALYSIS IN LAW}

As stated above, it is fair enough to assert that the notion of the network has been subsumed into legal scholarship, albeit certain vagueness has still existed. Anyway, this assertation could be the premise for a better comprehension of the concrete content concerning the network-oriented legal studies. You may have noticed that I tried to avoid reifying the concept of network in terms of its categories or types in the previous section. The reason refers to the complexity embedded in the typology of networks which, I think, deserves an independent section for clarification. In order to review the content of the network research in legal studies, Whalen (2016), for instance, divides legal network studies into four types, namely legal citation networks, statutory and regulatory networks, legal social networks, and criminology networks. To a certain extent, his division reaches the goal of being comprehensive. Yet, he merely takes account of the different ways in which scholars have applied the analytic techniques of network, i.e., the application of SNA. Other network studies that have nothing to do with SNA becomes a grey area consequently. Even though social network analytic 
techniques are dominant in the legal literature from a quantitative point of view, the profound value attached to the rests should not be overlooked.

In general, the network research in legal scholarship is full of variety in terms of its content. First of all, specific concerns with distinctive networks have already been permeated into many branches of law or subdisciplines. It is evidently difficult to enumerate all of them due to the space limitation, yet, among others, the constitutional law (Agnoloni, 2015), administrative law, criminal law, corporate law, contract law, environmental law, intellectual property law, and human rights law are most frequently involved in this enterprise (e.g., Chané \& Sharma, 2017). The law in these studies refers to not only statutes but also cases. However, the similarity is that both types of law are mainly studied under the banner of legal citation networks. These citation network analyses are beneficial from the availability and accessibility of legal (big) data against a more general backdrop of the breakthrough of the computational capacity. Also because of this, these networks can be uniformly categorized as the information network. Besides, another salient feature of the existing research is the multidimensional attribute of law. In other words, these extant studies include law at different levels. As to the domestic law, U.S., Germany and The Netherlands are widely and deeply involved. Nevertheless, network studies of law transcend the domestic level. EU law, international law, transnational law, and global law are popular topics in the literature as well.

Furthermore, judges and lawyers are 'celebrities' for the network research on law. Unlike the abovementioned information networks, this type of research primarily focuses on the structural patterns of these legal actors' social relations and the implications of network structures for their legal behaviors. Based on this focus, these legal actors are rigorously analyzed by network approaches in various forms. Taking lawyers as an example, Whalen (2016: 552) summarizes:

\begin{abstract}
'Network approaches have been used to explore how lawyers balance intrafirm pressures to cooperate and compete, how firm members spread the costs of protecting resources across their social networks, how collegiality manifests in social networks within firms, how large firms create international networks of lawyers and legal knowledge by posting lawyers in various offices, and how firm network structure predicts information flow and service pricing'.
\end{abstract}

Changing into another dimension, it is evident that network studies thoroughly go through each phase of the law, i.e., legislation, judiciary, and law enforcement. Correspondingly, there are legislative networks, judicial networks, and law enforcement networks in the literature. It is also noteworthy that all of these types of networks are composed of both information networks and social networks. Taking legislative networks analysis as an example, legal scholars and computer scientists collaboratively regard legislation as a complex network, as legislation which consists of an extensive collection of different normative documents increases in both size and complexity (Koniaris et al., 2014). Meanwhile, the characteristics of a 'small world' network in Congress are also observed (Tam Cho \& Fowler, 2010). More than Congress, legislators are also found more likely to coveted if they share more caucus connections in research that seeks to explore the consequences of partisan polarization in Congress and whether legislator takes steps to alleviate them (Victor et al., 2013). In fact, there are even more studies on judicial networks from various perspectives and by distinctive methods. For instance, Dallara and Amato (2012: 1) provide us with a wide-ranging perspective of understanding judicial networks by asserting that:
'Judicial network can be described as groups, conferences, commissions or organizations of legal experts, judges, and academics (coming for different countries) established at transnational level. Overall, the activities of these networks can be summarized as an exchange of ideas and practices, in the production of recommendations, opinions and best practices, concerning different fields of law and functioning of judicial system, and in the organization of seminars, conference and training of judges and legal experts'.

However, this inclusive understanding does not satisfy those who believe that judges exclusively formulate the judicial networks in question. Regardless of whether judicial networks are perceived through the broad or narrow vein, they all agree that 'social structure, and the formal and informal interactions between judicial actors, at least in part, chart the course of doctrinal development' (Katz and Stafford, 2010: 459). Furthermore, they all believe especially that the impact of 'judicial peer effects' on a certain legal decision due to the account that 'jurist either formally or informally consider the views of their colleagues' in the decision-making process (Ibid: 460).

Although these consensuses do exist among scholars, network studies exhibit some dissimilarities with respect to the contents. For instance, in addition to the research on legislative networks at the domestic level, more publications concentrate on transnational judicial networks. They affirm that although 'judges in different jurisdictions look different and behave differently: training, staffing, jurisdiction, powers, impact, and stature differ a great deal' (de Visser and Claes, 2013: 346), judicial networks have been increasingly diffused across sovereign states. Moreover, transnational judicial networks are consequently included within the framework of global governance by, especially, Anne-Marie Slaughter, who hammers away at a global community of courts which is constituted by the self-awareness of the national and international judges who play a part' (Slaughter, 2003: 192). Meanwhile, she believes that taking constitutional courts as an example, judges are also meeting face to face 'in these conferences and seminars exchange precedents and personal experiences, creating judicial networks that are powerful channels for cross-fertilization' (Ibid, 216-7). Another example is that while some scholars choose to study the formal judicial networks, others prefer to deal with the informal ones. The 
former refers to a variety of institutionalized networks, whereas the latter represents "the "judicial communities" or "epistemic communities" underlying them, or on informal and occasional contact between judiciaries and their members' (de Visser and Claes, 2013: 346). By the way, they also distinguish the horizontal judicial networks from the vertical judicial networks. According to them, horizontal networks are 'networks which bring together judges which are more or less at the same level and have similar functions in different legal systems or different regimes' (Ibid).

Additionally, there is a small part of literature that is more or less incompatible with the aforementioned logic of classification, i.e., roughly classified by either law branch or phase of the legal system. Nevertheless, they are of significance for configuring the network studies of law. Research on network externality is one of them. Originally, network externality, or network effect, is an idea from the economics of networks (Economides, 1996). Actually, the law does operate with these network characteristics. For instance, standard-form terms in Contract Law may 'generate network benefits since it reduces the cost of professional legal services in the future for others involved in similar transactions' (Ogus, 2011: 167-8). Therefore, to a large extent, research on network effects and law is comparatively prosperous, although Druzin (2009: 5) reminds that 'the application of network theory on legal process has not been fully developed, nor the full extent of its implications properly assessed'.

\section{“INSTITUTIONALIZATION SYMPTOM" OF THE NETWORK RESEARCH ON LAW}

An institutionalization symptom has been looming over us if we are taking a panoramic view of the network research in legal scholarship, albeit the picture is too fuzzy to be easily recognized. Moreover, just because of this ambiguous trait, it seems inappropriate to declare the actual existence of institutionalization of the network-oriented legal research. However, some collective endeavors, explicitly or implicitly, in this field have already appeared in various forms and by scholars with different intellectual backgrounds. With regard to the participants, it is evident that (academic) lawyers are not the exclusive protagonist.

On the contrary, one of the most salient features of the network research in the legal domain is associated with the extensive cooperation between legal scholars and some scholars coming from other disciplines or fields of inquiry. They are mainly sociologists, computer scientists, political scientists, mathematicians, physicians, and so forth. The multiauthorship could prove this feature in the existing literature. Also, based on the existing literature, it is discernible that the combination of lawyers or political scientists with computer scientists is the most pervasive pattern of cooperation. It indirectly demonstrates the fact that the technical and quantitative attributes of the network research have been taking a dominant position in legal scholarship. Apart from the comparatively complex composition of the participants, the multidisciplinary capacity of these involved legal scholars is another trait. For instance, some of them are scientists, technologists, and law professors at the same time. Accordingly, it helps to explain the perception of network research in legal studies as a multidisciplinary field as well in this regard.

In addition to the exponential expansion in terms of the participants for the development of network research in the legal field, this trend could also be identified from various kinds of academic activities. Among others, the increasing number of conferences is one of the most visible signs implying the preliminary aggregation of the epistemic community. For example, the first workshop specifically concerning Network Analysis in Law was organized by Radboud Winkels of the University of Amsterdam, together with others and in conjunction with the International Conference on AI and Law, in 2013. Subsequently, they respectively organized the $2^{\text {nd }}$ and $3^{\text {rd }}$ International Workshop on Network Analysis in Law in 2014 and 2015. These workshops mainly invited different kinds of original works that focus on: (1) analysis and visualization of networks of people and institutions; (2) analysis and visualization of the network of law; and (3) combination of the first and second aspects (Winkels \& Lettieri, 2014). Besides, the Center for the Study of Law \& Society at the University of California organized a workshop Social Network Analysis in Socio-legal Research within the framework of the Empirical Research Methods Workshops in 2011, providing an introduction to social networks under a confident presumption that social networks are powerful theoretical and methodological approach that can shed new lights on socio-legal research.

Books and journals have made equally important contributions to the development of network-oriented legal studies. First of all, there are some books, either monography or edited collection, to represent the growing attention to this field. These books actually attend to distinctive aspects of network research. Unlike its dominant position of SNA, the notion of the network in these legal books is rather descriptive and qualitative. It is also worth noting that some books are the results of the aforementioned academic activities. Another bastion for claiming the network research in the legal domain as a scholarly field refers to academic journals. Although a journal that exclusively focuses on network and law does not exist, other types of journals have played a vital role in pushing the institutionalization trend by publishing individual articles or even special issues. These journals include not only law journals but also journals with a particular interest in networks.

Internet is another platform to show the emergence and development of network research on law. Besides, it also functions as one of the major channels to disseminate profound ideas embedded in the network paradigm. Hereinto, academic blogs are playing a primary role. For instance, a Network Analysis and Law Tutorial is included in the blog Computational Legal Studies. Moreover, based on this specific site, more and more network-related information has been circulating with the underlying emphasis of the application of network analysis as an analytical method that radically rooted in the Computational Social Sciences in legal studies. In addition, The Faculty Lounge, a law professor blog designed to feel like 
a faculty lounge with conversations about law, culture, and academia, organized a series of network-related posts to reveal its significance of the legal network analysis. These examples, to some extent, imply the converging consensus among certain groups of scholars on the necessity, importance, and urgency of paying particular attention to the network research in the legal domain.

\section{CONCLUSION}

In conclusion, this paper has comprehensively reviewed the existing network research in legal scholarship by mainly attending to its origin, conception, content, and institutionalization. By doing so, this paper found that, in the macro sense, it is rational and reasonable to celebrate the benign development of network studies in the legal domain. More ambitiously, this paper has underlyingly contended that some early, sporadic, and even unconscious signals of accelerating network studies of law as an independent (sub)field of academic research have already emerged. In addition, the main concrete findings of this paper are concluded as follows: first of all, the rise of the network research on the law was aligned with the general popularity of the network paradigm in social sciences. In this sense, the origin and development of network analysis on law have been in line with the mainstream of network analysis/science, especially in terms of the historical timeline and scope; secondly, network research on law did inherit many features of general network analysis. Among others, the "structure-centered" approach, i.e., exclusively focusing on the structural issues of networks and relations, is the most common heritage. This study shows that the majority of network research on law focused on the structural dimension and its implications for law; thirdly, network studies were mainly regarded as an analytical technique in the current legal world in which the quantitative methodology and concrete methods (and methods) enjoyed the dominant position; last but not the least, although some signals demonstrated the formulation of institutionalization of network research on law, this paper also found that it was still in the early stage of its development due to the current lack of, for instance, professional associations, independent conferences, specific textbooks, and courses.

\section{LIMITATIONS AND STUDY FORWARD}

This study has its own limitations both from the perspectives of methodology and analytical deepness. Methodologically speaking, given the qualitative nature of the present study for which descriptive methods were preferably utilized, it seems noticeable that the literature review conducted in this study is difficult to be subsumed into a systematic pattern. Thus, it is reasonable to recommend that a variety of quantitative methods should be employed in future research to more comprehensively and statistically delineate the configuration of this emerging interdisciplinary area of study bridging legal and network sciences. Additionally, another limitation in terms of analysis in the present study is not only caused by the space constraint but also attributed to the firm commitment of its research aim itself. In order to broaden and deepen the discussion in question, subsequent research is expected: one, to retrospect and update the evolution and development of network(-oriented) research in different branches of law respectively. In this vein, comparative and critical works in the intellectual enterprise of "law and network" are highly anticipated; two, to further clarify the metatheoretical or philosophical foundations of the interdisciplinary research on "law and network" by seriously attending to both legal and network theories; three, reversely, to identify the implications of this comparatively new field of research for academic lawyers and social scientists particularly and the academia as a whole.

\section{ACKNOWLEDGMENT}

I would like to express my sincere gratitude to my supervisors Prof. Andrea De Guttry (Scuola Superiore Sant'Anna) and Prof. Koen De Feyter (University of Antwerp) for their valuable guidance and support throughout the duration of this research. Besides, I would also like to thank the peer reviewers and editors who provided their constructive comments and suggestions. However, all the remaining errors are mine alone.

\section{REFERENCES}

1. Agnoloni, T. (2015). Network Analysis of Italian Constitutional Case Law. In Semantic Processing of Legal Texts (SPLeT-2014) (pp. 151-155).

2. Amstutz, M., \& Teubner, G. (Eds.). (2009). Networks: Legal Issues of Multilateral Co-operation. Portland: Hart Publishing.

3. Augsberg, I., Viellechner, L., \& Zumbansen, P. (2009). Introduction to the Special Issue: The Law of the Network Society. A Tribute to Karl-Heinz Ladeur. German Law Journal, 10(4), 305-309. https://doi.org/10.1017/S2071832200001085

4. Berry, F. S., Brower, R. S., Choi, S. O., Goa, W. X., Jang, H., Kwon, M., \& Word, J. (2004). Three traditions of network research: What the public management research agenda can learn from other research communities. Public Administration Review, 64(5), 539-552. https://doi.org/10.1111/j.1540-6210.2004.00402.x

5. Borgatti, S. P., Mehra, A., Brass, D. J., \& Labianca, G. (2009). Network Analysis in the Social Sciences. Science, 323(April), 892-896. https://doi.org/10.1126/science.1165821

6. Buxbaum, R. M. (1993). Is "Network" a Legal Concept? Journal of Institutional and Theoretical Economics, 149(4), 698-705.

7. Castells, M. (2000). Materials for an Exploratory Theory of the Network Society. The British Journal of Sociology, 51(1), 5-24. https://doi.org/10.1080/000713100358408 
8. Chané, A.-L., \& Sharma, A. (2017). Social Network Analysis in Human Rights Research. In B. A. Andreassen, H.-O. Sano, \& S. McInerney-Lankford (Eds.), Research Methods in Human Rights: A Handbook (pp. 354-378). Cheltenham: Edward Elgar Publishing Limited. https://doi.org/10.4337/9781785367793.00023

9. Christakis, N. A., \& Fowler, J. H. (2011). Connected: The Surprising Power of Our Social Networks and How They Shape Our Lives. New York: Little, Brown.

10. Cotterrell, R. (2008). Community as a Legal Concept? Some Uses of a Law-And-Community Approach in Legal Theory. In R. Cotterrell (Ed.), Living Law: Studies in Legal and Social Theory (pp. 17-28). Farnham: Ashgate.

11. Dallara, C., \& Amato, R. (2012). Judicial and Legal Expert Networks. New Actors for a EU Area of Justice? In National Courts vis-a-vis EU Law: New Issues, Theories \& Methods, European University Insitute (pp. 1-3).

12. de Visser, M., \& Claes, M. (2013). Judicial Networks. In P. Larouche \& P. Cserne (Eds.), National Legal Systems and Globalization (pp. 345-370). The Hague: Springer. https://doi.org/10.1007/978-90-6704-885-9 13

13. Dothan, S. (2018). Social Networks and the Enforcement of International Law. In M. Hirsch \& A. Lang (Eds.), Research Handbook on the Sociology of International Law (pp. 333-346). Edward Elgar Publishing. https://doi.org/10.4337/9781783474493.00023

14. Druey, J. N. (2009). The Path to the Law - The Difficult Legal Access of Networks. In M. Amstutz \& G. Teubner (Eds.), Networks: Legal Issues of Multilateral Co-operation (pp. 87-102). Portland: Hart Publishing.

15. Druzin, B. (2009). Buying Commercial Law: Choice of Law, Choice of Forum, and Network Externalities. Tulane Journal of International \& Comparative Law, 18, 131.

16. Economides, N. (1996). The Economics of Networks. International Journal of Industrial Organization, 14(September 1994), 673-699. https://doi.org/10.1016/0167-7187(96)01015-6

17. Erickson, M. (2012). Network as Metaphor. International Journal of Criminology and Sociological Theory, 5(2), 912-921.

18. Freeman, L. (2011). The Development of Social Network Analysis - With an Emphasis on Recent Events. The Sage Handbook of Social Network Analysis, 26-54. https://doi.org/10.1016/j.socnet.2005.01.010

19. Gallagher, J. J., \& Anderson, C. W. (1999). Designing, implementing, and reporting research: The significant role of literature review. Journal of Research in Science Teaching, 36(6), 619-620. https://doi.org/10.1002/(SICI)1098-2736(199908)36:6<619::AID-TEA2>3.0.CO;2-B

20. Hafner-Burton, E. M., Kahler, M., \& Montgomery, A. H. (2009). Network Analysis for International Relations. International Organization, 63(3), 559-592. https://doi.org/10.1017/S0020818309090195

21. Harris, P. (1982). Structural Change in the Communication of Precedent among State Supreme Courts, 18701970. Social Networks, 4, 201-212. https://doi.org/10.1016/0378-8733(82)90021-1

22. Katz, D. M., \& Stafford, D. K. (2010). Hustle and Flow: A Social Network Analysis of the American Federal Judiciary. Ohio State Law Journal, 71(3), 457-507.

23. Kemmerer, A. (2009). The Normative Knot 2.0: Metaphorological Explorations in the Net of Networks. German Law Journal, 10(4), 439-462. https://doi.org/10.1017/S2071832200001152

24. Kjaer, P. F. (2009). Embeddedness through Network: A Critical Appraisal of the Network Concept in the Oeuvre of Karl-Heinz Ladeur. German Law Journal, 10(4), 483-500. https://doi.org/10.1017/S2071832200001176

25. Knox, H., Savage, M., \& Harvey, P. (2006). Social networks and the study of relations: networks as method, metaphor and form. Economy and Society, 35(1), 113-140. https://doi.org/10.1080/03085140500465899

26. Koniaris, M., Anagnostopoulos, I., \& Vassiliou, Y. (2014). Legislation as a Complex Network: Modeling and Analysis of European Union Legal Sources. In R. Hoekstra (Ed.), Legal Knowledge and Information Systems (Vol. 5, pp. 143--143-). IOS Press.

27. Ladeur, K.-H. (1997). Towards a Legal Theory of Supranationality - The Viability of the Network Concept. European Law Journal, 3(1), 33-54. https://doi.org/10.1111/1468-0386.00018

28. Ladeur, K.-H. (2007). The Role of Contracts and Networks in Public Governance: The Importance of the Social Epistemology" of Decision Making. Indiana Journal of Global Legal Studies, 14(2), 329-351. https://doi.org/10.2979/gls.2007.14.2.329

29. Latour, B. (2011). Networks, Societies, Spheres: Reflections of an Actor- Network Theorist. International Journal of Communication, 5(February), 796-810.

30. Levi, R., \& Valverde, M. (2008). Studying Law by Association: Bruno Latour Goes to the Conseil d'État. Law \& Social Inquiry, 33(3), 805-825. https://doi.org/10.1111/j.1747-4469.2008.00122.x

31. Lewis, T. G. (2009). Network Science: Theory and Practice. Wiley Publishing. https://doi.org/10.1002/9780470400791

32. Ogus, A. (2011). Legal Systems as Networks. In M. Faure \& J. Smits (Eds.), Does Law Matter?: On Law and Economic Growth (pp. 165-177). Cambridge: Intersentia.

33. Petersen, N., \& Towfigh, E. V. (2017). Network Analysis and Legal Scholarship. German Law Journal, 18(3). https://doi.org/10.1017/S2071832200022124

34. Puig, S. (2018). Network Analysis and the Sociology of International Law. In M. Hirsch \& A. Lang (Eds.), Research Handbook on the Sociology of International Law (pp. 319-332). Edward Elgar Publishing. https://doi.org/10.4337/9781783474493.00022

35. Slaughter, A.-M. (2003). A Global Community of Courts. Harvard International Law Journal, 44(1), $191-219$. 
36. Smith, T. A. C. (2005). The web of law. San Diego Legal Studies Research Paper, 6(11), 1-39. https://doi.org/10.2139/ssrn.642863

37. Tam Cho, W. K., \& Fowler, J. H. (2010). Legislative Success in a Small World: Social Network Analysis and the Dynamics of Congressional Legislation. Journal of Politics, $72(1), \quad 124-135$. https://doi.org/10.1017/S002238160999051X

38. Teubner, G. (2009a). And if I by Beelzebub Cast out Devils,...": An Essay on the Diabolics of Network Failure. German Law Journal, 10(4), 395-416. https://doi.org/10.1017/S2071832200001139

39. Teubner, G. (2009b). Coincidentia Oppositorum: Hybrid Networks Beyond Contract and Organisation. In M. Amstutz \& G. Teubner (Eds.), Networks: Legal Issues of Multilateral Co-operation (pp. 3-30). Portland: Hart Publishing.

40. Victor, J. N., Ringe, N., \& Haptonstahl, S. (2013). Multiplex Legislative Networks and the Power of Caucuses to Alleviate Partisan Polarization. Working Papers 69. https://opensiuc.lib.siu.edu/pn_wp/69

41. Watts, D. J. (2004). The "New" Science of Networks. Annual Review of Sociology, 30(1), $243-270$. https://doi.org/10.1146/annurev.soc.30.020404.104342

42. Whalen, R. (2016). Legal Networks: The Promises and Challenges of Legal Network Analysis. Michigan State Law Review, 539-565.

43. Winkels, R., \& Lettieri, N. (Eds.). (2014). 2nd International Workshop on "Network Analysis in Law." Retrieved from http://www.leibnizcenter.org/ winkels/NAiL2014-pre-proceedings.pdf 